\title{
A New Method for Surface Modifications of Carbon Steels and Alloys
}

\author{
Valeriy Dondokovich Dugar-Zhabon , Hector Jaime Dulcé Moreno ${ }^{\mathrm{b}}$, \\ Hernán Alfonso Garnica Villamizarc, Ely Dannier Valbuena Niño ${ }^{\mathrm{a}, \mathrm{d} *}$
}

\author{
aPlasma Physics and Technology Group - FITEK, Universidad Industrial de Santander, \\ A.A. 678, Bucaramanga, Santander, Colombia \\ ' Investigation in Ceramics Technology Group - GITEC, Universidad Francisco de Paula Santander, \\ A.A. 1055, Cúcuta, Norte de Santander, Colombia \\ 'Investigation Corporation for Corrosion - CIC, Piedecuesta, Santander, Colombia \\ ${ }^{\mathrm{d}}$ Investigation in Plasma Technology Group - GINTEP, Universidad Pontificia Bolivariana, \\ A.A. 2932, Bucaramanga, Santander, Colombia
}

Received: March 15, 2011; Revised: July 3, 2012

\begin{abstract}
A three-dimensional treatment method involving implantation of ions into solids immersed in a high voltage pulse discharge ignited on the left-hand-branch of the Paschen curve was elaborated about fifteen years ago. This method, named 3DII for short, has been used in the equipment JUPITER (Joint Universal Plasma and Ion Technologies Experimental Reactor) for practical purposes. Hereafter, the need for better means to improve the metal surface protection against aggressive media prompted an elaboration of the MOSMET concept which is based on a hybrid treatment involving the processes of implantation and deposition. It is significant that the processes can be set into action simultaneously or separately. In this article, the conditions of hybrid treatment of AISI SAE 1010, 1020 y 1045 carbon steels, their subsequent electrochemical diagnostics and corrosion test results are described. The corrosion rate of the samples treated by titanium hybrid discharge is found approximately an order of magnitude smaller as compared to the non-treated samples.
\end{abstract}

Keywords: high-voltage discharge, electric arc, titanium surface treatment

\section{Introduction}

As of now, there is a strong trend towards the implementation of gas discharges to treat solids in order to enhance their resistance to corrosion processes. In this area, we have started with the gas ion implantation study ${ }^{1-4}$. The implantation is performed through high voltage pulse discharges ignited in the JUPITER reactor which is set up in Plasma Physics Laboratory at the Universidad Industrial de Santander (Colombia). In order to implant metal ions, the JUPITER reactor was supplemented by an arc vaporizing equipment. This modified reactor is named MOSMET ${ }^{5}$. It is significant that the MOSMET reactor permits not only to deposit metal vapor or molecules ( such as $\mathrm{TiN}_{2}$ ) on the surface through the arc discharge or the ion implantation through the high voltage discharge but also to give a hybrid treatment which is realized at simultaneous functioning of the electric arc discharge and the high voltage discharge related to the left branch of the Paschen curve ${ }^{6,7}$.

The hybrid treatment of metals which modifies the structure of their surface and sub-surface layers can improve such characteristics as the surface microhardness and resistance to corrosion including resistance to corrosion produced by biologic species ${ }^{8,9}$. The surface treatment technologies based on the hybrid discharge can successfully be applied in the petrochemical industry, medicine industry, electronics and material sciences. A brief description of the MOSMET facility and the hybrid treatment effect on the

*e-mail: ely.valbuena@upb.edu.co corrosion resistance of AISI SAE 1010, 1020, and 1045 steel types are given below.

\section{Experimental Setup}

The MOSMET reactor is in fact the JUPITER reactor supplemented with an electric arc discharge system, which makes it possible to treat metal samples in gas discharges or metal vapor discharges, or by mixed metal vapor - gas discharges.

The general set-up of the MOSMET equipment is presented in Figure 1 (the left hand side). The right hand side on Figure 1 shows the electric scheme of the arc equipment and its position in the reactor chamber with the dimensions of $80 \times 70 \times 70 \mathrm{~cm}^{3}$. The high voltage $(\mathrm{HV})$ rectangular pulses elaborated by an electronic device, which is based on a high voltage pulse transformer, are imposed across the HV cathode (see Figure 1, the left hand side). The arc cathode and the HV cathode are set on the opposite sides of the chamber in order to create favorable conditions to the arc discharge metal ions to be implanted into the metal samples arranged on the HV cathode surface through the electric contact with it. The cathode separation is as long as $35 \mathrm{~cm}$. The arc and HV equipments are electrically isolated despite the fact that the chamber walls serve as the anode in both schemes. By this expedient the arc discharge and HV discharge are operated independently without mutual perturbation, thus permitting to ignite either an 
arc discharge or an HV discharge, or both simultaneously. The latter case presents a hybrid discharge which provides a hybrid surface treatment. The chemical composition of the gas-vapor media in the chamber after and during the treatment processes is controlled by a mass-spectrometer HPQ2. The cathodes are water cooled, and their surface temperatures are measured through a sapphire window with an EIR-350 infrared thermometer.

\subsection{Coupon samples}

The samples used for hybrid treatment and the subsequent electrochemical testing are made of AISI SAE 1010, 1020 and 1045 steels as coupons of a rectangular form of $2.54 \times 1.27 \mathrm{~cm}$. The coupons are polished with 600 emery papers to make their surfaces clean and uniform and the preparation degree suits the SSPC-SP (white metal) which is specified by the ASTM G1-033 standard.

The hybrid treatment is realized through the imposition of $10 \mathrm{kV}$ pulses of $0.25 \mathrm{~ms}$ duration at $30 \mathrm{~Hz}$ repetition frequency on the arc plasma. The hybrid treatment time is limited by 10 minutes. The titanium deposition rate on the sample surface depends on the distance between the arc cathode and the sample, the arc current magnitude and the solenoid magnetic field have control of the arc discharge. With the arc current of $150 \mathrm{kA}$, the measured Ti deposition rate is $1.5 \mathrm{~nm} / \mathrm{s}$ which gives the Ti layer thickness a value of $6 \mu \mathrm{m}$. In the hybrid discharge, the implantation of ions occurs simultaneously with the deposition process. The ion implantation into the sample body is effective only during the first seconds or so. After this period of time the ions get implanted not into the sample body but into the deposited layer. The depth distribution of the implanted ions is obtained by using SIMS CAMECA equipment and TRIM code simulations ${ }^{10}$. It is found that the density of the implanted titanium atoms reaches its maximum at a depth of $5.8 \mathrm{~nm}$ from the sample surface and then it gradually decreases up to the depth $20 \mathrm{~nm}$. This is how a very thin subsurface layer system steel-Ti atoms is created, which washes away the substrate-layer interface and weakens the adhesion problem.

\subsection{Electrochemical parameters tests}

A change in the corrosion resistance of the steel coupons subjected to the titanium hybrid treatment is evaluated. To accelerate the physics-chemical corrosion processes, the treated and non-treated coupons are exposed to the standard $0.3 \%$ sodium chloride bride. The performance evaluation of the hybrid treatment as corrosion mitigation measure is carried out using the Tafel and linear polarization resistance (LPR) methods. The polarization and the Tafel curves are obtained with the help of an impedance measurement unit IM6 of Zhander Electric. The standard parameters of the electrochemical tests for the Tafel curves are presented in Table 1.
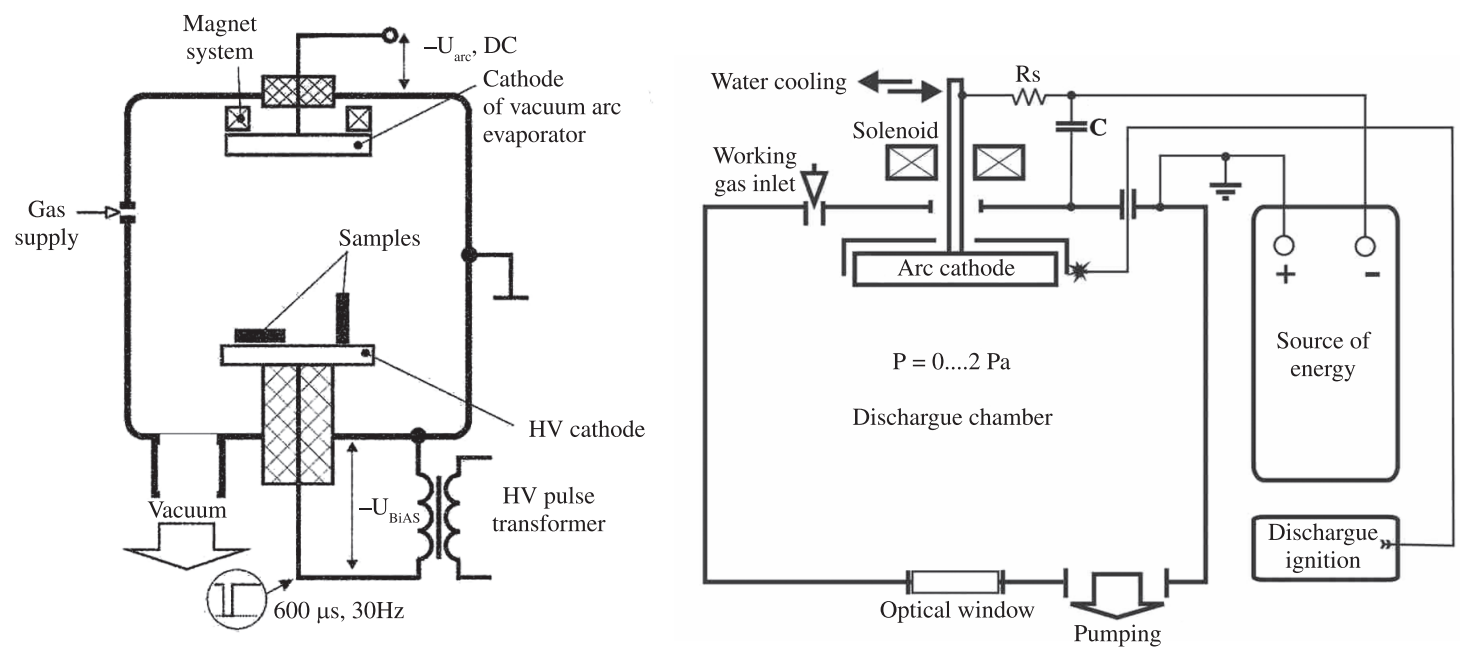

Figure 1. MOSMET chamber layout (left hand side) and the arc equipment electric scheme (right hand side).

Table 1. Electrochemical parameters test.

\author{
LRP voltage range \\ Tafel curve voltage range \\ Electrode material \\ Reference electrode \\ Auxiliary electrode material \\ $\mathrm{CO}_{2}$ partial pressure \\ Gas flow \\ Temperature \\ Electrolyte \\ Volume/area relation
}

\author{
$\pm 20 \mathrm{mV}$ at a rate of $200 \mu \mathrm{V} / \mathrm{seg}$ \\ $\pm 250 \mathrm{mV}$ at a rate of $200 \mu \mathrm{V} / \mathrm{seg}$ \\ API 5LX42 carbon steel \\ $\mathrm{Ag} / \mathrm{AgCl}$ \\ Platinum
}

1 bar (downstream pressure) $<10 \mathrm{SFCH}$

$30{ }^{\circ} \mathrm{C}$

Sodium chloride bride 


\section{Results}

\subsection{Linear polarization resistance}

To monitor the corrosion rate in a $3 \%$ aqueous solution, the effective linear polarization method is applied. The measurements of the current versus the applied potential which varies within a range of $\mathrm{mV}$ (see Table 1) permit to find the linear polarization resistance $\mathrm{Rp}$ of the solutions, which is a measure of the sample corrosiveness. It is important that such small voltages as $20 \mathrm{mV}$ should not affect the natural corrosion process. The extent to which the titanium hybrid treatment may exert a polarization resistance effect is presented in Figure 2 where the lower curve corresponds to the 1010 steel without treatment and the upper curve is obtained for this metal coupon which is put through a titanium hybrid treatment during 10 minutes. In these tests, the salt solution was saturated with carbon dioxide. Similar curves are obtained for other steel types under test. A decrease of the current value which

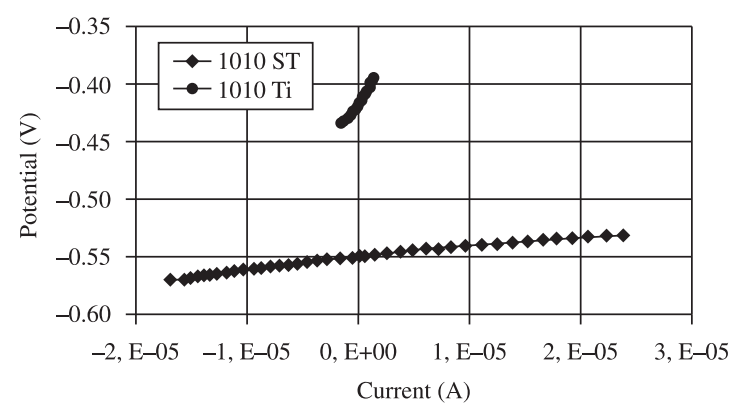

Figure 2. LPR curves measured with SAE 1010 steel: upper curve is for a Ti treated sample, the curve below is for non-treated sample.

Table 2. Polarization resistance of treated and non-treated coupons.

\begin{tabular}{ccc}
\hline Steel & \multicolumn{1}{c}{ Treatment } & $\begin{array}{c}\text { Averaged Rp } \\
(\mathbf{O h m})\end{array}$ \\
\hline 1010 & Without hybrid treatment & 938 \\
1010 & With Ti hybrid treatment & 13726 \\
1020 & Without hybrid treatment & 888 \\
1020 & With Ti hybrid treatment & 7481 \\
1045 & Without hybrid treatment & 1162 \\
1045 & With Ti hybrid treatment & 14344 \\
\hline
\end{tabular}

1010 steel sample with treatment

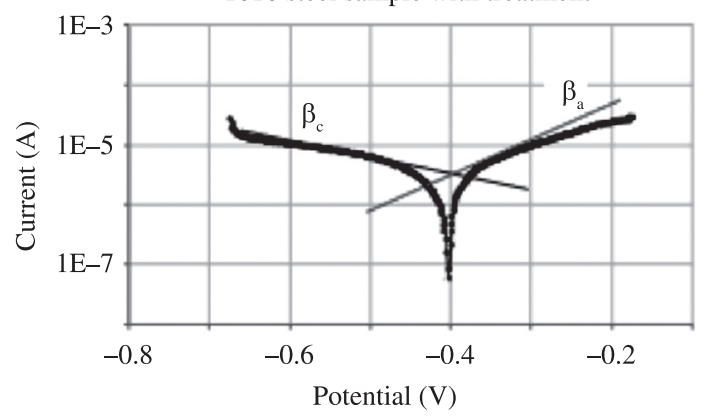

corresponds to enhancement in the polarization resistance is a diminishing measure of the mass transfer from the metal into the solution. The case presented by the upper curve in Figure 2 must be attributed to anticorrosive properties of the implanted and deposited titanium ions.

The data on the polarization resistances for all the tested steel types are collected in Table 2. As one can observe, the titanium hybrid treatment of the tested metals improves drastically the corrosion resistance.

\subsection{Tafel slopes}

Another method for determining the metal loss by a steel sample whose surface is in contact with a corrosion solution is the Tafel method. The Tafel slopes making it possible to measure the metal corrosion rate are the parts of the semi-logarithm Tafel diagram. These parts are presented by the straight lines ranging usually from the point located in $50 \mathrm{mV}$ from the corrosion potential. The mode of determination of thermodynamical constants $\beta$ on the voltamperic Tafel diagrams are demonstrated in Figure 3 where one can see that there are significant differences between the tangents to the anodic y cathode branches of the Tafel slopes obtained for the treated and non-treated 1010 steel coupons. The cathode slopes $\beta \mathrm{c}$ and anode slopes $\beta$ a calculated for all the evaluated systems metal-bride saturated with $\mathrm{CO}_{2}$ are done in Table 3 .

\subsection{Corrosion rate calculations}

The polarization resistance curves and the Tafel slopes make it possible to determine the corrosion current density $i_{\text {corr }}$ whose expression, in accordance with the ASTM G102-99 standard, is given as

$$
i_{\text {corr }}=\frac{\beta_{a} \beta_{c}}{2.3\left(\beta_{a}+\beta_{c}\right)(R p) A}
$$

where $A$ is the sample area which contacts the electrolyte in $\mathrm{cm}^{2}, \beta \mathrm{c}$ and $\beta \mathrm{a}$ are in V/dec and $\mathrm{Rp}$ in $M \Omega$. Using the derived values for the corrosion currents, the corrosion rate $\mathrm{Vel}_{\text {corr }}$ is calculated in mpy units:

$$
V e l_{\text {corr }}(\text { mpy })=(0.13)\left(i_{\text {corr }}\right) \frac{W_{e}}{d}
$$

where $i_{\text {corr }}$ in $\mu \mathrm{A} . \mathrm{cm}^{-2}$, We is the electrochemical equivalent and $d$ is the sample material density in $\mathrm{g}_{\mathrm{cm}} \mathrm{cm}^{-3}$. The data

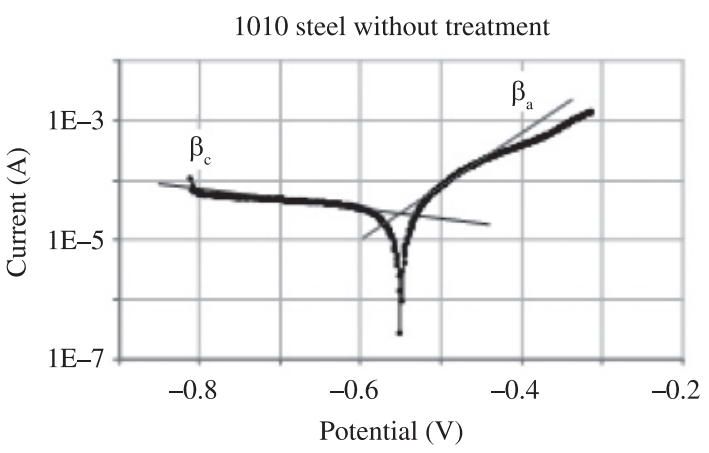

Figure 3. Tafel slopes for AISI SAE 1010 steel: with treatment - left hand side, without treatment - right hand side. 
Table 3. Values of $\beta$ obtained for each evaluated system.

\begin{tabular}{lccc}
\hline Steel & Treatment & $\beta \mathbf{a}\left(\mathbf{m V . d e c} \mathbf{~}^{-1}\right)$ & $\beta \mathbf{c}\left(\mathbf{m V . d e c} \mathbf{- 1}^{-1}\right)$ \\
\hline 1010 & Without treatment & 122.0 & 604 \\
1010 & With Ti hybrid treatment & 202.0 & 319 \\
1020 & Without treatment & 112.0 & 558 \\
1020 & With Ti hybrid treatment & 217.0 & 182 \\
1045 & Without treatment & 92.6 & 573 \\
1045 & With Ti hybrid treatment & 275.0 & 173 \\
\hline
\end{tabular}

Table 4. Corrosion rate values for the evaluated systems.

\begin{tabular}{ccccccrr}
\hline Steel & Treatment & $\begin{array}{c}\text { Area } \\
\left(\mathbf{c m}^{2}\right)\end{array}$ & $\begin{array}{c}\text { We } \\
\left(\mathbf{g . g m o l}^{-\mathbf{1}}\right)\end{array}$ & $\begin{array}{c}\mathbf{D} \\
\left(\mathbf{g . c m}^{-3}\right)\end{array}$ & $\begin{array}{c}\mathbf{R p} \\
(\Omega)\end{array}$ & $\begin{array}{c}\mathbf{i}_{\text {corr }} \\
(\boldsymbol{\mu A . c m} \mathbf{- 2})\end{array}$ & $\begin{array}{c}\mathbf{V}_{\text {Corr }} \\
\left(\mathbf{m p y}^{-}\right)\end{array}$ \\
\hline 1010 & Without treatment & 1.00 & 27.923 & 7.86 & 938 & 47.02 & 22.22 \\
1010 & With Ti treatment & 1.00 & 27.923 & 7.86 & 13727 & 3.92 & 1.81 \\
1020 & Without treatment & 1.00 & 27.923 & 7.86 & 888 & 46.65 & 21.06 \\
1020 & With Ti treatment & 1.00 & 27.923 & 7.86 & 7482 & 5.75 & 2.65 \\
1045 & Without treatment & 1.00 & 27.923 & 7.86 & 1162 & 29.81 & 13.75 \\
1045 & With Ti treatment & 1.00 & 27.923 & 7.86 & 14344 & 3.21 & 1.48 \\
\hline
\end{tabular}

obtained in this way are shown in Table 4 and Figure 4. In Figure 4 the treated samples are marked with Ti while the non-treated ones are left unmarked.

The corrosion rates of the non-treated coupons are found higher than 13.75 mpy whereas those for the titanium hybrid treated coupons are found smaller than for the non-treated ones by a factor of $\mathrm{m}$ with the values of $m=12$ for 1010 steel, $m=7$ for 1020 steel and $m=9$ for 1045 steel. The corrosion rates are determined to an accuracy of $5 \%$. The treated 1045 steel demonstrates the best anticorrosive property (see Table 4).

Any alloy containing iron is subjected to a galvanic corrosion due to the interaction of iron with atmosphere or aqueous media. In this interaction, the iron atoms loose two electrons and as $\mathrm{Fe}^{++}$ions leave the metal surface producing pitting processes. The fact that the corrosion rate of samples treated in Ti discharge falls significantly suggests a drastic suppression of the reaction which transforms the atoms $\mathrm{Fe}$ into ions $\mathrm{Fe}^{+2}$.

\section{References}

1. Dougar-Jabon VD, Dulce Moreno J and Tsygankov PA. High voltage pulse discharge for ion treatment of metals. Review of Scientific Instruments. 2002; 73:828-830. http://dx.doi. org/10.1063/1.1429785

2. Dougar-Jabon VD, Dulce Moreno J and Tsygankov PA. Device JÚPITER for ion implantation. Revista Colombiana de Física. 1998; 30:181-184.

3. Valbuena Niño ED, Dulcé HJ and Dugar-Zhabon V. Caracterization of AISI 4140 Steel Implanted by Nitrogen Ions. Revista Colombiana de Física. 2010; 42(3):387-392.

4. Peña D, Fontalvo P, Estupiñan H, Valbuena Niño ED and Vesga W. Experimental Evaluation of Corrosion Resistance of an AISI-SAE 4140 Steel Implanted With Nitrogen Ions. Revista Dyna. 2009; 76(159):43-52.

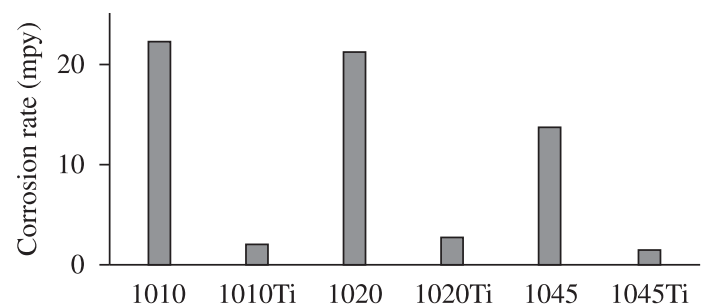

Figure 4. Comparison of the corrosion rates in the bride saturated with $\mathrm{CO}_{2}$ for different steels treated in the hybrid discharge (marked with $\mathrm{Ti}$ ) and the non-treated ones (unmarked).

\section{Conclusions}

The treatment of AISI SAE 1010, 1020 and 1045 steel samples is fulfilled in the MOSMET reactor by titanium hybrid discharges. The titanium hybrid treatment efficiency as an anticorrosive means for carbon steels is verified through using the LPR and Tafel electrochemical diagnostics. It is shown that this treatment can increase the resistance of 1010 , 1020 and 1045 steels to corrosive reactions by an order of magnitude. It is reasonable to suppose that the surface treatment of tools made of carbon steel or alloys in a high voltage titanium discharge can protect them efficiently against oxidation processes.

\section{Acknowledgements}

The authors thank the Corporation for Corrosion Research for the help in preparation of coupons. This work has been partially supported by Colciencias through the project MOSMET 1102-06-17823.

5. Valbuena Niño ED, Tsygankov P, Plata A, Ochoa C, Parada F, Chacón C et al. Study Of Volt-Ampere Carachteristics And Functioning Peculiarities Of A Vacuum Arc Sprayer. Revista Colombiana de Física. 2011; 43(2):458-462.

6. Khvesyuk VI and Tsygankov PA. The Use of a High-Voltage Discharge at Low Pressure for 3D Ion Implantation. Surface and Coatings Technology. 1997; 96:68-74. http://dx.doi. org/10.1016/S0257-8972(97)00117-5

7. Dulce Moreno JH, Tsygankov PA, Dugar-Zhabon VD, Valbuena Niño ED and Parada FF. Estudio de los Haces Electrónicos en la Descarga Eléctrica de Alto Voltaje a Bajas Presiones. Puente Revista Científica. 2011, 5(2):21-26.

8. Rao TS, Kora AJ, Anupkumar B, Narasimhan SV and Feser R. Pitting Corrosion of Titanium by a Freshwater Train of Suplase Reducing Bacteria (Desulfovidrio Vulgaris). Corrosion 
Science. 2005; 47:1071-1084. http://dx.doi.org/10.1016/j. corsci.2004.07.025

9. Zuo R, Ornek D, Syrett BC, Green RM, Hsu CH, Mansfeld FB et al. Inhibiting Mild Steel Corrosion From SulfateReducing Bacteria Using Antimicrobial-Producing Biofilms in Three-Mile-Island Process Water. Applied Microbiology and Biotechnology. 2004; 64:275-283. PMid:12898064. http:// dx.doi.org/10.1007/s00253-003-1403-7

10. Ziegler JF, Biersack JP and Ziegler MD. SRIM - The Stopping and Range of Ions in Matter. SRIM \& TRIM; 2008. p. 398. 